\title{
A breakthrough-like effect of metformin reduces peripheral resistance to triiodothyronine in euthyroid, non-insulin-resistant, type 2 diabetic patients
}

\author{
Melinda Kertész ${ }^{1}$, Szilárd Kun ${ }^{1}$, Eszter Sélley ${ }^{1}$ Zsuzsanna Nagy', Tamás Kőszegi ${ }^{2}$ and István Wittmann ${ }^{1}$ \\ 'Department of Medicine and Nephrology-Diabetes Centre, Medical School, University of Pécs, Pécs, Baranya, Hungary \\ ${ }^{2}$ Department of Laboratory Medicine, Medical School, University of Pécs, Pécs, Baranya, Hungary \\ Correspondence should be addressed to I Wittmann: wittmann.istvan@pte.hu
}

\begin{abstract}
Background: Type 2 diabetes is characterized, beyond the insulin resistance, by polyhormonal resistance. Thyroid hormonal resistance has not yet been described in this population of patients. Metformin is used to decrease insulin resistance, and at present, it is assumed to influence the effect of triiodothyronine, as well.

Methods: In this open-label, pilot, hypothesis-generating, follow-up study, 21 patients were included; all of them were euthyroid with drug naïve, newly diagnosed type 2 diabetes. Before and after 4 weeks of metformin therapy, fructosamine, homeostasis model assessment for insulin resistance (HOMA-IR), thyroid hormones, T3/T4 ratio, and TSH, as well as blood pressure and heart rate using ambulatory blood pressure monitor were measured. We also conducted an in vitro study to investigate the possible mechanisms of T3 resistance, assessing T3-induced Akt phosphorylation among normal $(5 \mathrm{mM})$ and high $(25 \mathrm{mM})$ glucose levels with or without metformin treatment in a human embryonal kidney cell line.

Results: Metformin decreased the level of T3 $(P<0.001)$, the ratio of T3/T4 $(P=0.038)$, fructosamine $(P=0.008)$ and HOMA-IR $(P=0.022)$. All these changes were accompanied by an unchanged TSH, T4, triglyceride, plasma glucose, bodyweight, blood pressure, and heart rate. In our in vitro study, T3-induced Akt phosphorylation decreased in cells grown in $25 \mathrm{mM}$ glucose medium compared to those in $5 \mathrm{mM}$. Metformin could not reverse this effect.

Conclusion: Metformin seems to improve T3 sensitivity in the cardiovascular system in euthyroid, type 2 diabetic patients, the mechanism of which may be supracellular.
\end{abstract}
Key Words
- insulin resistance
- metformin
- ratio of T3/T4
- triiodothyronine resistance
- type 2 diabetes mellitus

\section{Introduction}

Insulin resistance related to glucotoxicity and lipotoxicity is a well-described phenomenon $(1,2)$. It is also known that in insulin-resistant patients other hormonal resistance may occur (e.g. resistance to leptin and FSH $(3,4)$.

It is generally accepted that insulin resistance is mainly due to a postreceptorial defect, which is caused by signaling abnormalities. However, one can suppose that hormones with similar signaling pathways may have similar postreceptorial derangements.

Insulin signaling uses many pathways, but the glucometabolic effect is mediated through a PI3K route. Canonical intracellular signaling of free triiodothyronine https://ec.bioscientifica.com

https://doi.org/10.1530/EC-21-0218

C) 2021 The authors Published by Bioscientifica Ltd

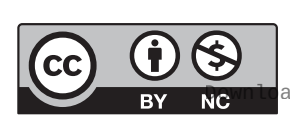

This work is licensed under a Creative Commons Attribution-NonCommercial 4.0 International License. ded from Bioscientifica.com at 04/26/2023 07:52:30AM 
(T3) in turn, the so-called type 1 and 2 pathway, involves direct and indirect DNA-binding. On the other hand, noncanonical type 3 signaling is a thyroid receptor-dependent, non-genomic pathway using phosphorylations and PI3K, and noDNA-binding (5). T3 induces Akt phosphorylation in rodent skeletal muscle, post-infarcted myocardium, and in 3T3-L1 adipocytes $(6,7,8)$, which also indicates an insulinlike effect. While the hypothalamic-pituitary-thyroid axis is thought to be determined by the canonical pathway, the cardiometabolic (heart rate, body temperature, glucose, and triglyceride) effects of $\mathrm{T} 3$ are supposed to be mediated by the non-canonical pathway (9). Thus, at the PI3K level, insulin and non-canonical T3 signaling converge.

Many authors suggest that in patients with obesity and insulin resistance, thyroid abnormalities could also be present. When analyzing the National Health and Nutrition Examination Survey (NHANES) data, it could be verified that low T3 is associated with the decrease of HOMA-IR (10), which is a parameter of insulin resistance. In another study, the association of subclinical hypothyroidism and complications of type 2 diabetes was proved (11). Recently, an increased prevalence of nodular thyroid disease in metabolic syndrome has been detected (12). Moreover, high T3 may predict metabolic syndrome: a $50-80 \%$ increase in the risk of metabolic syndrome has been detected in the highest quartile compared to the lowest quartile of T3 level (13). Thus, both in non-diabetic and diabetic patients, HOMA-IR correlates with TSH, which association is tighter in those diabetics who have a higher hemoglobin $\mathrm{A}_{1 \mathrm{c}}\left(\mathrm{HbA}_{1 \mathrm{c}}\right)$ (14). On the other hand, Ferrannini et al. proved that insulin resistance, measured by the clamp technique, indirectly and through many metabolic steps leads to the elevation of T3 (15).

In another analysis of the above-mentioned NHANES database, it was shown that the T3/T4 ratio, which is a marker of the deiodinase reaction, was positively associated with HOMA-IR (16).

In clinical practice, HOMA-IR is used for the estimation of insulin resistance, but the question arises of how possible resistance to thyroid hormones can be detected. In clinical settings, the central nervous and cardiovascular systems are the target organs of T3. In the CNS, T3, in a negative feedback loop, decreases the secretion of thyrotropin (TSH). In the cardiovascular system, T3 increases blood pressure and heart rate. So, besides measuring the serum level of thyroid hormones (T3, T4), their physiological effects (e.g. on TSH level, blood pressure, and heart rate) should also be measured.

Metformin is used in prediabetes and in type 2 diabetic patients to treat insulin resistance resulting in a decreased level of plasma glucose and triglycerides, leading in this way to a lowering of glucotoxicity and lipotoxicity. A rapidly decreasing glucotoxicity can have an important effect on cellular metabolism. This process is supposed to be in the background of a 'breakthrough phenomenon', which is well described in connection with insulin resistance (17, 18). The breakthrough method is used almost exclusively in newly diagnosed diabetic patients with insulin resistance.

One might hypothesize that being an insulin sensitizer metformin could have a similar sensitizer effect in the case of T3 in insulin-resistant, type 2 diabetic patients. Hence, we aimed to investigate the effect of metformin in euthyroid, metformin-naïve, newly diagnosed type 2 diabetic patients, measuring insulin resistance, thyroid hormones, glucose-, and lipid metabolism, as well as TSH, blood pressure, and heart rate.

\section{Materials and methods}

\section{Clinical protocol}

In this open-label, pilot, hypothesis-generating, follow-up study, 21 patients were included between 40 and75 years of age, who were euthyroid and drug naïve, with a newly diagnosed type 2 diabetes. The study was approved by the Regional Committee for Research Ethics, University of Pécs (No: 7282). Baseline clinical characteristics are shown in Table 1.

Exclusion criteria were previously initiated metformin therapy or other antidiabetic therapy and known thyroid disease, or treatment with LT4.

Patients provided a signed informed consent after being informed about the study protocol.

Before starting metformin treatment and after 4 weeks of an uptitration of metformin (during the first 2 weeks of $500 \mathrm{mg}$, and up to 4 weeks of $1000 \mathrm{mg}$ ), the blood was taken from the patients, and the following parameters were measured and calculated: TSH, T3, T4, T3/T4 ratio, thyrotroph thyroid hormone sensitivity index $(\mathrm{TTSI}=100 \times \mathrm{TSH}(\mathrm{mU} / \mathrm{L}) \times \mathrm{fT} 4(\mathrm{pmol} / \mathrm{L}) /$ assayspecific upper limit of the reference interval for fT4 concentration $(\mathrm{pmol} / \mathrm{L}))$, thyroid feedback quantilebased index (TFQI $=$ population empirical cumulative distribution function to hormone concentration (cdf) fT4 - (1-cdf TSH)), fructosamine, triglyceride, HOMA-IR (= fasting plasma glucose $(\mathrm{mmol} / \mathrm{L}) \times$ fasting plasma insulin $(\mathrm{pmol} / \mathrm{L}) / 22.5)$, plasma glucose, and plasma insulin. The rationale of measuring merely fructosamine and not $\mathrm{HbA}_{1 \mathrm{c}}$ is the 4 -week duration of our study. Serum samples were

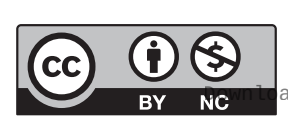

This work is licensed under a Creative Commons Attribution-NonCommercial 4.0 International License. ded from Bioscientifica.com at 04/26/2023 07:52:30AM 
Table 1 Baseline characteristics of the patients.

\begin{tabular}{|c|c|}
\hline Variables & $\mathbf{n}=\mathbf{2 1}$ \\
\hline Age (year) & $55 \pm 12$ \\
\hline Male (\%) & $14(67)$ \\
\hline \multicolumn{2}{|l|}{ Metabolic } \\
\hline Bodyweight (kg) & $93 \pm 17$ \\
\hline BMI $\left(\mathrm{kg} / \mathrm{m}^{2}\right)$ & $31.6 \pm 5.0$ \\
\hline Fasting plasma glucose (mmol/L) & $7.6 \pm 3.3$ \\
\hline HOMA-IR & $2.6 \pm 1.3$ \\
\hline \multicolumn{2}{|l|}{ Thyroid } \\
\hline TSH (mU/L) & $2.2 \pm 1.2$ \\
\hline fT3 (pmol/L) & $5.2 \pm 0.6$ \\
\hline fT4 (pmol/L) & $16.7 \pm 2.9$ \\
\hline fT3/fT4 & $0.3 \pm 0.1$ \\
\hline \multicolumn{2}{|l|}{ Blood pressure, heart rate } \\
\hline Systolic BP (mmHg) & $134 \pm 13$ \\
\hline Diastolic BP (mmHg) & $77 \pm 9$ \\
\hline Heart rate (b.p.m) & $75 \pm 10$ \\
\hline \multicolumn{2}{|l|}{ Drug therapy } \\
\hline \multicolumn{2}{|l|}{ Antihypertensives } \\
\hline ACE inhibitors (\%) & $14(67)$ \\
\hline Calcium channel blockers (\%) & $9(43)$ \\
\hline Diuretics (\%) & $7(33)$ \\
\hline Statin $(\%)$ & $6(29)$ \\
\hline Aspirin (\%) & $2(10)$ \\
\hline \multicolumn{2}{|l|}{ Risk factors } \\
\hline Hypertension (\%) & $18(86)$ \\
\hline Dyslipidemia (\%) & $12(57)$ \\
\hline Obesity (\%) & $14(67)$ \\
\hline Smoking (\%) & $4(19)$ \\
\hline \multicolumn{2}{|l|}{ Comorbidities } \\
\hline AMI (\%) & $0(0)$ \\
\hline Stroke $(\%)$ & $0(0)$ \\
\hline Amputation (\%) & $0(0)$ \\
\hline Atrial fibrillation (\%) & $1(5)$ \\
\hline
\end{tabular}

Reference values for TSH were 0.270-4.200 mU/L; for fT3, 3.1-6.8 pmol/L and for fT4, 12.00-22.00 pmol/L.

$\mathrm{AMI}$, acute myocardial infarction; BP, blood pressure; fT3, triiodothyronine; fT4, thyroxine; HOMA-IR, homeostasis model assessment-estimated insulin resistance; TSH, thyroid-stimulating hormone.

analyzed by routine laboratory tests using fully automated instrumentation (Roche) in our University's accredited centralized laboratory. Blood pressure and heart rate were measured using ambulatory blood pressure monitor (ABPM04, ABPM Art Ltd.). In the statistical analysis, we used the following blood pressure (BP) and heart rate parameters: mean systolic BP, mean diastolic BP, mean arterial pressure and mean pulse pressure, as well as mean, maximum, minimum, and the standard deviation of the heart rate.

\section{In vitro study}

We also conducted an in vitro study to investigate the possible mechanisms of T3 resistance. For this purpose, we used a human embryonal kidney (HEK293) cell line (ATCC ${ }^{\circ}$ CRL-11268 ${ }^{\mathrm{TM}}$ ) maintained in Dulbecco's modified Eagle's medium (DMEM, Invitrogen, CAT number: 41966029; Sigma Aldrich CAT number: D6046) with 10\% fetal bovine serum (Gibco, CAT number: 16170-078), $100 \mathrm{U} / \mathrm{mL}$ penicillin, and $0.1 \mathrm{mg} / \mathrm{mL}$ streptomycin (Gibco, CAT number: 15070-063), $2 \mu \mathrm{g} / \mathrm{mL}$ Fluconazole (Fresenius Kabi Hungary), $5 \mathrm{mM}$ glucose and $398 \mathrm{nM}$ p-Tyr. Cells were grown in a humidified incubator at $37^{\circ} \mathrm{C}$ and $5 \% \mathrm{CO} 2$. Then, this medium was changed to media containing 5 or $25 \mathrm{mM}$ glucose. Cells were cultured among these circumstances for 5 days. Afterward, we applied an overnight incubation with serum-free medium. Then, cells in 5 and $25 \mathrm{mM}$ glucose were treated with $\mathrm{T} 3(0,0.1,0.3$, $1 \mathrm{nM}$ ), and another group of cells in $25 \mathrm{mM}$ glucose with $\mathrm{T} 3(0,0.1,0.3,1 \mathrm{nM})$ and metformin $(10 \mathrm{mM})$ for $20 \mathrm{~min}$. After this treatment, they were washed twice with PBS at $4^{\circ} \mathrm{C}$, then were scraped off mechanically in the presence of radio-immunoprecipitation assay (RIPA) lysis buffer and were frozen at $-80^{\circ} \mathrm{C}$.

Finally, Western blot analysis was performed using p-Akt and total Akt staining. Cell lysates were centrifuged (10 $\mathrm{min}, 11,000 \mathrm{~g}, 4^{\circ} \mathrm{C}$ ). Protein content of samples was determined by the Bradford method using BSA as a standard (Bio-Rad Benchmark Plus). Samples were solubilized in a buffer of $100 \mathrm{mmol} / \mathrm{L}$ Tris- $\mathrm{HCl}$ (pH 6.8), 4.0\% sodium dodecyl sulfate (SDS), $20 \%$ glycerol, $200 \mathrm{mmol} / \mathrm{L}$ DTT, and $0.2 \%$ bromophenol blue. Samples ( $80-120 \mu$ g protein) were electrophoretically resolved on polyacrylamide gels (10\%) and transferred in a buffer ( $\mathrm{pH} 8.3$ ) containing $38 \mathrm{mmol} / \mathrm{L}$ glycine, $48 \mathrm{mmol} / \mathrm{L}$ Tris-base, and 20\% methanol to PVDF membranes (Amersham-Biotech) for $90 \mathrm{~min}$ at $250 \mathrm{~mA}$. Membranes were washed with TBS-T $0.1 \%$ and incubated in peroxidase-conjugated IgG secondary antibody diluted in TBS-T with 5\% BSA to 1:2000 with anti-rabbit polyclonal anti-phospho-(Ser473)-Akt (Cell Signaling Technology, \#7074 ) to detect p-Akt overnight. To reprobe Western blots with alternative primary antibodies for total total PKB/ Akt (\#9272, Cell Signaling Technology), membranes were stripped as follows: membranes were washed in stripping buffer, containing $1.5 \%$ glycine, $0.1 \%$ SDS, $1 \%$ Tween- 20 at pH 2.2, for $2 \times 10 \mathrm{~min}$, then washed in PBS $0.1 \%$ for $2 \times 5$ $\mathrm{min}$, then washed in TBS-T $0.1 \%$ for $2 \times 5 \mathrm{~min}$. Thereafter, blots were incubated with the primary antibody as described above. Blots were detected using a secondary antibody (anti-rabbit IgG, HRP-linked, \#7074, Cell Signaling dissolved in TBS-T with 5\% BSA) and enhanced chemiluminescence (ECL; Pierce Biotech, Bio-Rad). Computerized densitometry (integrated optical density) of the specific bands was analyzed with Scion Image for

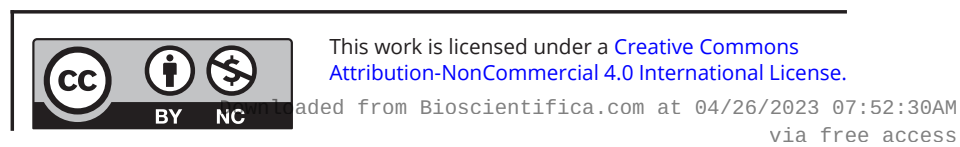


Windows Software. Protein signals were corrected for total Akt protein levels and were adjusted for controls.

\section{Statistical analysis}

We used the Statistical Package for the Social Sciences (SPSS) software, version 24.0 (IBM Corporation) for the statistical analysis. The Kolmogorov-Smirnov test was used to test normality, in cases of normal distribution mean \pm S.D. were given, and a paired sample $t$-test was applied, while in the case of non-normal distribution, Mann-Whitney $U$-test was used. Values of $P<0.05$ were considered as significant.

\section{Results}

\section{Metformin reduces T3, T3/T4 ratio, fructosamine, and HOMA-IR}

After 4 weeks of metformin therapy, a highly significant decrease was found in the level of T3 (Fig. 1 panel A). Interestingly, the ratio of T3/T4 was also diminished (Fig. 1 panel $\mathrm{B}$ ). We measured fructosamine instead of $\mathrm{HbA}_{1 \mathrm{c}}$ because of the short duration of the study (4 weeks), in which value was also lower after the 4 weeks of metformin treatment (Fig. 1 panel C). HOMA-IR representing insulin resistance showed a decrease, as well (Fig. 1 panel D).

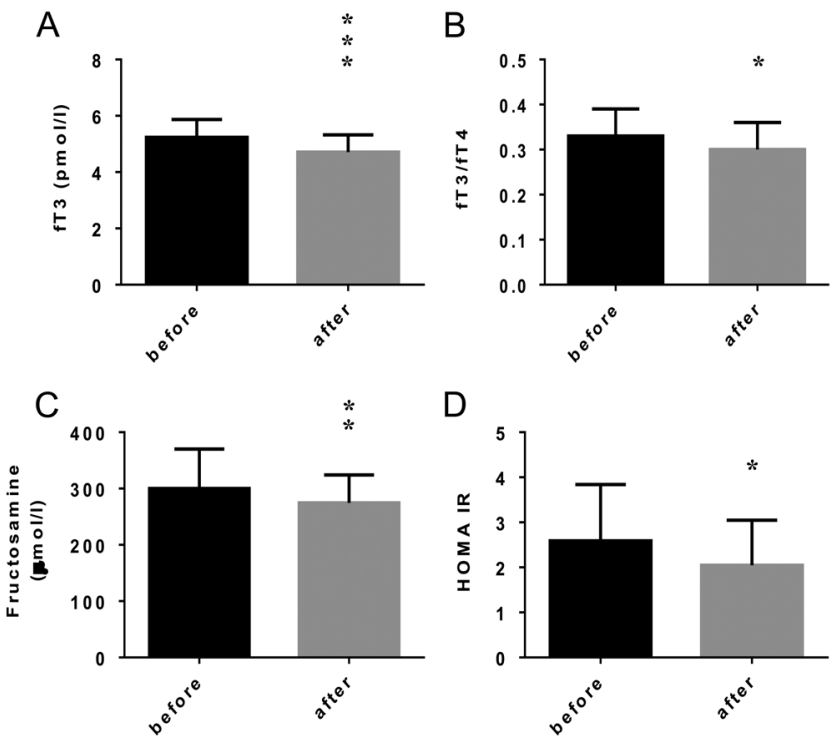

Figure 1

Significant decrease in the level of T3 $(A)$, ratio of T3/T4 (B), fructosamine (C), and HOMA-IR (D) after treatment with metformin. ${ }^{*} P<0.05$ vs before $\star \star P<0.01$ vs before; ${ }^{* \star} * P<0.001$ vs before. Whiskers represent S.D.

\section{Parameters remained unchanged}

We would like to highlight that, in spite of, the significant decrease in the level of T3, fructosamine, HOMA-IR and the ratio of T3/T4, levels of TSH, T4, TTSI, TFQI triglyceride, plasma glucose, plasma insulin, and all values of blood pressure and heart rate remained unchanged (Table 2).

\section{Akt phosphorylation}

According to the results of six series of measurements, T3 treatment (0.1, 0.3 and $1 \mathrm{nM})$-induced Akt phosphorylation in HEK293 cells grown in a medium containing $5 \mathrm{mM}$ glucose. On the contrary, no elevation in p-Akt/Akt ratio was detected in those cultured in $25 \mathrm{mM}$ glucose and $25 \mathrm{mM}$ glucose with metformin (Fig. 2).

\section{Discussion}

The main findings of our pilot study were the following:

(i) in euthyroid, newly diagnosed, type 2 diabetic, drug naïve patients, metformin reduces both the level of T3 and ratio of $\mathrm{T} 3 / \mathrm{T} 4$;

(ii) in the same population of patients, metformin decreases fructosamine and HOMA-IR;

(iii) despite these changes, TSH, T4, blood pressure, and heart rate remained unchanged;

(iv) high glucose concentration decreased T3-induced Akt phosphorylation in a human cell line;

(v) metformin could not reverse this effect.

In our study, metformin decreased the fructosamine level, while the serum insulin level remained unchanged proving that a better glycemia could be achieved with the same insulin. This being a sign of improvement of insulin resistance mirroring in the decrease of the value of HOMA-IR, as well. In the case of thyroid hormones, we do not have a specific parameter for $\mathrm{T} 3$ resistance, as we do with HOMA-IR for insulin resistance, but the lower T3 level with the same TSH, blood pressure, and heart rate means the same as the decrease of HOMA-IR for the insulin resistance, that is, the decrease of the T3 resistance.

Our results provide a new terminology to be used in type 2 diabetic patients, namely that the term 'T3 resistance' could be applied in euthyroid patients.

Our study is not the first to use metformin in type 2 diabetes to study thyroid function but all others have wanted to examine metformin's effect in either subclinical hypothyroid $(19,20,21)$, or in treated overt hypothyroid

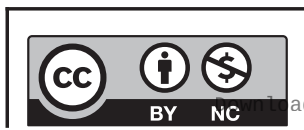

This work is licensed under a Creative Commons Attribution-NonCommercial 4.0 International License. ded from Bioscientifica.com at 04/26/2023 07:52:30AM 
Table 2 Changes of parameters of thyroid, metabolic, blood pressure and heart rate after 4 weeks of metformin therapy.

\begin{tabular}{|c|c|c|c|c|c|}
\hline & \multicolumn{2}{|c|}{ Before } & \multicolumn{2}{|c|}{ After } & \multirow[b]{2}{*}{$\boldsymbol{p}$} \\
\hline & Mean & S.D. & Mean & S.D. & \\
\hline \multicolumn{6}{|l|}{ Thyroid } \\
\hline TSH (mU/L) & 2.2 & 1.2 & 2.2 & 1.2 & 0.986 \\
\hline fT4 (pmol/L) & 16.7 & 2.9 & 16.1 & 3.1 & 0.097 \\
\hline fT3 (pmol/L) & 5.3 & 0.7 & 4.7 & 0.6 & $<0.001$ \\
\hline fT3/fT4 & 0.325 & 0.065 & 0.302 & 0.065 & 0.038 \\
\hline TTSI & 172 & 96 & 164 & 92 & 0.707 \\
\hline TFQI & 0.546 & 0.298 & 0.526 & 0.304 & 0.939 \\
\hline \multicolumn{6}{|l|}{ Metabolic } \\
\hline $\begin{array}{l}\text { Triglyceride } \\
(\mathrm{mmol} / \mathrm{L})\end{array}$ & 2.3 & 1.6 & 2.0 & 1.0 & 0.285 \\
\hline $\begin{array}{l}\text { Plasma glucose } \\
\text { (mmol/L) }\end{array}$ & 7.6 & 3.3 & 6.6 & 1.5 & 0.058 \\
\hline $\begin{array}{l}\text { Plasma insulin } \\
\text { (pmol/L) }\end{array}$ & 128.3 & 68.1 & 102.1 & 57.2 & 0.111 \\
\hline HOMA-IR & 2.5 & 1.2 & 2.1 & 1.0 & 0.022 \\
\hline HOMA- $\beta$ & 83.3 & 59.9 & 86.5 & 49.7 & 0.880 \\
\hline $\begin{array}{l}\text { Fructosamine } \\
(\mu \mathrm{mol} / \mathrm{L})\end{array}$ & 304.3 & 74.7 & 274.7 & 52.8 & 0.008 \\
\hline Bodyweight (kg) & 93 & 17 & 93 & 18 & 0.910 \\
\hline \multicolumn{6}{|l|}{ Blood pressure } \\
\hline $\begin{array}{l}\text { Systolic BP } \\
(\mathrm{mmHg})\end{array}$ & 134 & 13 & 134 & 16 & 0.584 \\
\hline $\begin{array}{l}\text { Diastolic BP } \\
(\mathrm{mmHg})\end{array}$ & 77 & 9 & 76 & 9 & 0.151 \\
\hline $\mathrm{MAP}(\mathrm{mmHg})$ & 96 & 10 & 95 & 10 & 0.280 \\
\hline $\begin{array}{l}\text { Pulse pressure } \\
(\mathrm{mmHg})\end{array}$ & 57 & 11 & 58 & 12 & 0.648 \\
\hline \multicolumn{6}{|l|}{ Heart rate } \\
\hline Mean (b.p.m) & 75 & 10 & 77 & 8 & 0.782 \\
\hline $\begin{array}{l}\text { Maximum } \\
\text { (b.p.m) }\end{array}$ & 113 & 29 & 114 & 25 & 0.269 \\
\hline $\begin{array}{l}\text { Minimum } \\
\text { (b.p.m) }\end{array}$ & 58 & 7 & 60 & 8 & 0.158 \\
\hline s.D. (b.p.m) & 11 & 4 & 11 & 4 & 0.056 \\
\hline
\end{tabular}

BP, blood pressure; fT4, thyroxine; fT3, triiodothyronine; HOMA-IR, homeostasis model assessment-estimated insulin resistance; HOMA- $\beta$, homeostasis model assessment-estimated $\beta$-cell function; MAP, mean arterial pressure; S.D., standard deviation; TSH, thyroid-stimulating hormone; TTSI, thyrotroph thyroid hormone resistance index; TFQI, thyroid feedback quantile-based index.

patients $(22,23)$, in amiodarone-induced hypothyroidism (24), or in polycystic ovary syndrome women with subclinical hypothyroidism (25), or elsewhere, where the prevalence of hypothyroidism was detected in the course of metformin therapy (26). The populations of these studies are not comparable with our population, because our patients were euthyroid and type 2 diabetic.

Another group of previous clinical studies focused on the changes of TSH on metformin therapy. One of them concluded that there is no association between TSH and metformin treatment in type 2 diabetes (27). In a real-world study, using a database, hypothyroid and euthyroid type
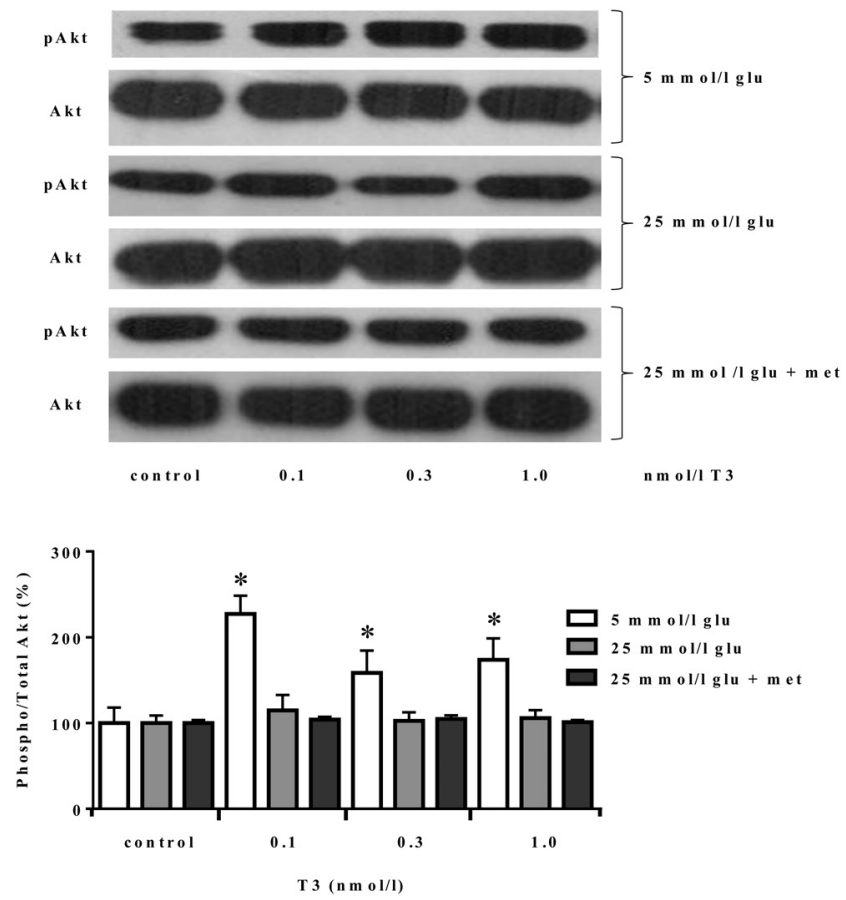

Figure 2

T3-induced Akt phosphorylation in human embryonal kidney (HEK293) cells among normal (5 mM) and high ( $25 \mathrm{mM})$ glucose levels with or without metformin treatment. ${ }^{*} P<0.05$ vs control. Data presented as mean \pm S.E.M.

2 diabetic patients were compared, and it was concluded that in euthyroid diabetic patients metformin use was not associated with a decrease of TSH (28). Neither TSH nor T4 was changed during a 12-month metformin therapy in euthyroid, and type 2 diabetic patients (29). These studies proved the same as our observation, namely that metformin therapy does not change the TSH level.

On the other hand, there are some studies showing decreasing TSH levels as a result of metformin therapy $(30,31)$. Still, there are significant differences between the above-mentioned populations and ours. In those studies, non-diabetic patients or subjects with insulin resistance with benign thyroid nodules have been examined, and the study period was longer (usually 6 months, or longer). In our study, on the other hand, patients with newly diagnosed type 2 diabetes were included, with unknown thyroid disease, and a short-term (1 month) treatment was applied, focusing on the breakthrough-like effect of metformin. These differences in the settings could be potential explanations for the different behavior of TSH levels among the studies. Unchanged TSH together with decreasing T3-level induced by metformin in our study may prove the remission of $\mathrm{T} 3$ resistance in our patients. https://ec.bioscientifica.com

https://doi.org/10.1530/EC-21-0218 (c) 2021 The authors Published by Bioscientifica Ltd
This work is licensed under a Creative Commons Attribution-NonCommercial 4.0 International License. ded from Bioscientifica.com at 04/26/2023 07:52:30AM 
However, the most important comment on the above-mentioned papers is that they did not examine the possibility of $\mathrm{T} 3$ resistance. If randomized controlled trials were to support our observations that metformin is able to improve $\mathrm{T} 3$ resistance, this could add to our understanding of polyhormonal resistance in type 2 diabetes and may further justify the metformin position as a first-line drug in the management of these patients. On the other hand, it would be interesting to examine the effects of other antidiabetic drugs in decreasing insulin resistance (e.g. sodium-glucose cotransporter- 2 inhibitors or GLP-1 receptor agonists) on the $\mathrm{T} 3$.

There are some other important data related to the T3 level and T3/T4 ratio in obese patients (32). After 6 months of gastric banding of obese patients, BMI, waist circumference, triglyceride, blood glucose, serum insulin, HOMA-IR, T3, and T3/T4 decreased, TSH remained unchanged, and T4 increased. This metformin-like effect of gastric banding on thyroid hormones further supports our results. Conversion of T4 to T3 is dependent on deiodinase enzymatic activity. Type 2 isoform (D2) of deiodinase, supposed to produce T3, is activated by PI3K-signalling of insulin (33), which pathway is suppressed in insulinresistant state. If the metformin effect would be mediated by this insulin-deiodinase mechanism, the T3 level should be increased after metformin; however, just the opposite changes could be registered in our study. Taken these into consideration, changes of T3/T4 in our study were very similar to that seen in gastric banding, but the regulation of these changes is not related to the improvement of insulin sensitivity, rather independent modulation should be supposed.

Neither TTSI nor TFQI values showed significant changes, which is not surprising, as neither T4 nor TSH changed in our study. Those authors who examined population-wide indices made a remark that in their analysis T3 was excluded from the model and that is why these indices are characteristic only for T4 (34). Concerning TFQI, it is an important fact that this calculation method was established for the US population, whereas Hungarian subjects may have different values.

In our in vitro study, metformin could not reverse the detrimental effect of high glucose levels on Akt phosphorylation. Thus, the favorable effects observed on metabolic state may be mediated by other changes, for example, via incretin hormones or altered gut flora.

The limitations of our study are (i) the relatively low number of cases, (ii) the short duration, and (iii) the generally known, quite low reliability of the laboratory measurements of free thyroid hormones, especially T3.
In summary, metformin decreases insulin and T3 resistance in the first month of the treatment, which is accompanied by the decrease of $\mathrm{T} 3 / \mathrm{T} 4$ ratio. A decrease in $\mathrm{T} 3$ resistance could play a role in the beneficial metabolic effects of metformin. Mechanisms in the background of the metformin effect are not known.

\section{Declaration of interest}

The authors declare that there is no conflict of interest that could be perceived as prejudicing the impartiality of the research reported.

\section{Funding}

This research did not receive any specific grant from any funding agency in the public, commercial or not-for-profit sector.

\section{Acknowledgements}

The authors thank all colleagues, who helped in the recruitment of the patients: Brigitta Kovács, Kinga Ezer, Krisztina Horváth, Zita Barta, János Princz, Andrea Kis, Mónika Bányai.

\section{References}

1 Burén J, Lindmark S, Renström F \& Eriksson JW. In vitro reversal of hyperglycemia normalizes insulin action in fat cells from type 2 diabetes patients: is cellular insulin resistance caused by glucotoxicity in vivo? Metabolism: Clinical and Experimental 200352 239-245. (https://doi.org/10.1053/meta.2003.50041)

2 DeFronzo RA. Insulin resistance, lipotoxicity, type 2 diabetes and atherosclerosis: the missing links. The Claude Bernard Lecture 2009. Diabetologia 201053 1270-1287. (https://doi.org/10.1007/s00125-0101684-1)

3 Könner AC \& Brüning JC. Selective insulin and leptin resistance in metabolic disorders. Cell Metabolism 201216 144-152. (https://doi. org/10.1016/j.cmet.2012.07.004)

4 La Vignera S, Condorelli RA, Duca Y, Cannarella R, Giacone F \& Calogero AE. FSH treatment for normogonadotropic male infertility: a synergistic role for metformin? European Review for Medical and Pharmacological Sciences 201923 5994-5998. (https://doi. org/10.26355/eurrev_201907_18346)

5 Flamant F, Cheng SY, Hollenberg AN, Moeller LC, Samarut J, Wondisford FE, Yen PM \& Refetoff S. Thyroid hormone signaling pathways: time for a more precise nomenclature. Endocrinology 2017 158 2052-2057. (https://doi.org/10.1210/en.2017-00250)

6 de Lange P, Senese R, Cioffi F, Moreno M, Lombardi A, Silvestri E, Goglia F \& Lanni A. Rapid activation by 3,5,3'-L-triiodothyronine of adenosine $5^{\prime}$-monophosphate-activated protein kinase/acetylcoenzyme A carboxylase and Akt/protein kinase B signaling pathways: relation to changes in fuel metabolism and myosin heavy-chain protein content in rat gastrocnemius muscle in vivo. Endocrinology 2008149 6462-6470. (https://doi.org/10.1210/en.20080202)

7 Mourouzis I, Giagourta I, Galanopoulos G, Mantzouratou P, Kostakou E, Kokkinos AD, Tentolouris N \& Pantos C. Thyroid hormone improves the mechanical performance of the post-infarcted diabetic myocardium: a response associated with up-regulation of Akt/mTOR and AMPK activation. Metabolism: Clinical and Experimental 201362 1387-1393. (https://doi.org/10.1016/j.metabol.2013.05.008)

8 Lin Y \& Sun Z. Thyroid hormone promotes insulin-induced glucose uptake by enhancing Akt phosphorylation and VAMP2 translocation 
in 3T3-L1 adipocytes. Journal of Cellular Physiology 2011226 2625-2632. (https://doi.org/10.1002/jcp.22613)

9 Sebastian Hönes G, Rakov H, Logan J, Liao XH, Werbenko E, Pollard AS, Præstholm SM, Siersbæk MS, Rijntjes E, Gassen J, et al. Noncanonical thyroid hormone signaling mediates cardiometabolic effects in vivo. PNAS 2017114 E11323-E11332. (https://doi. org/10.1073/pnas.1706801115)

10 Wang CY, Yu TY, Shih SR, Huang KC \& Chang TC. Low total and free triiodothyronine levels are associated with insulin resistance in non-diabetic individuals. Scientific Reports 20188 10685. (https://doi. org/10.1038/s41598-018-29087-1)

11 Han C, He X, Xia X, Li Y, Shi X, Shan Z \& Teng W. Subclinical hypothyroidism and type 2 diabetes: a systematic review and metaanalysis. PLoS ONE 201510 e0135233. (https://doi.org/10.1371/journal. pone.0135233)

12 Tsatsoulis A. The role of insulin resistance/hyperinsulinism on the rising trend of thyroid and adrenal nodular disease in the current environment. Journal of Clinical Medicine 20187 37. (https://doi. org/10.3390/jcm7030037)

13 Wolffenbuttel BHR, Wouters HJCM, Slagter SN, van Waateringe RP, Muller Kobold AC, van Vliet-Ostaptchouk JV, Links TP \& van der Klauw MM. Thyroid function and metabolic syndrome in the population-based LifeLines cohort study. BMC Endocrine Disorders 2017 17 65. (https://doi.org/10.1186/s12902-017-0215-1)

14 Zhu P, Liu X \& Mao X. Thyroid-stimulating hormone levels are positively associated with insulin resistance. Medical Science Monitor 201824 342-347. (https://doi.org/10.12659/msm.905774)

15 Ferrannini E, Iervasi G, Cobb J, Ndreu R \& Nannipieri M. Insulin resistance and normal thyroid hormone levels: prospective study and metabolomic analysis. American Journal of Physiology: Endocrinology and Metabolism 2017312 E429-E436. (https://doi.org/10.1152/ ajpendo.00464.2016)

16 Le TN, Celi FS \& Wickham EP. Thyrotropin levels are associated with cardiometabolic risk factors in euthyroid adolescents. Thyroid 201626 1441-1449. (https://doi.org/10.1089/thy.2016.0055)

17 Højberg PV, Vilsbøll T, Rabøl R, Knop FK, Bache M, Krarup T, Holst JJ $\&$ Madsbad S. Four weeks of near-normalisation of blood glucose improves the insulin response to glucagon-like peptide- 1 and glucose-dependent insulinotropic polypeptide in patients with type 2 diabetes. Diabetologia 200952 199-207. (https://doi.org/10.1007/ s00125-008-1195-5)

18 Vilsbøll T, Krarup T, Madsbad S \& Holst JJ. Defective amplification of the late phase insulin response to glucose by GIP in obese Type II diabetic patients. Diabetologia 200245 1111-1119. (https://doi. org/10.1007/s00125-002-0878-6)

19 Krysiak R, Szkróbka W \& Okopień B. Effect of metformin on hypothalamic-pituitary-thyroid axis activity in elderly antipsychotictreated women with type 2 diabetes and subclinical hypothyroidism: a preliminary study. Journal of Clinical Pharmacology 201858 586-592. (https://doi.org/10.1002/jcph.1048)

20 Krysiak R, Szkróbka W \& Okopień B. Sex-dependent effect of metformin on hypothalamic-pituitary-thyroid axis activity in patients with subclinical hypothyroidism. Pharmacological Reports 201668 1115-1119. (https://doi.org/10.1016/j.pharep.2016.07.002)

21 Dornelles Severo M, Stürmer Andrade T, Correa Junior V, Antonio Naujorks A, Gus M \& Schaan BD. Metformin effect on TSH in subclinical hypothyroidism: randomized, double-blind, placebocontrolled clinical trial. Endocrine 201859 66-71. (https://doi. org/10.1007/s12020-017-1462-7)
22 Cappelli C, Rotondi M, Pirola I, Agosti B, Formenti A, Zarra E, Valentini U, Leporati P, Chiovato L \& Castellano M. Thyreotropin levels in diabetic patients on metformin treatment. European Journal of Endocrinology 2012167 261-265. (https://doi.org/10.1530/EJE-120225)

23 Isidro ML, Penín MA, Nemiña R \& Cordido F. Metformin reduces thyrotropin levels in obese, diabetic women with primary hypothyroidism on thyroxine replacement therapy. Endocrine $2007 \mathbf{3 2}$ 79-82. (https://doi.org/10.1007/s12020-007-9012-3)

24 Krysiak R, Gilowska M, Szkróbka W \& Okopień B. The effect of metformin on the hypothalamic-pituitary-thyroid axis in patients with type 2 diabetes and amiodarone-induced hypothyroidism. Pharmacological Reports 201668 490-494. (https://doi.org/10.1016/j. pharep.2015.11.010)

25 Krysiak R \& Okopien B. The effect of metformin on the hypothalamicpituitary-thyroid axis in women with polycystic ovary syndrome and subclinical hypothyroidism. Journal of Clinical Pharmacology 201555 45-49. (https://doi.org/10.1002/jcph.373)

26 Distiller LA, Polakow ES \& Joffe BI. Type 2 diabetes mellitus and hypothyroidism: the possible influence of metformin therapy. Diabetic Medicine 201431 172-175. (https://doi.org/10.1111/dme.12342)

27 Díez JJ \& Iglesias P. Relationship between serum thyrotropin concentrations and metformin therapy in euthyroid patients with type 2 diabetes. Clinical Endocrinology 201378 505-511. (https://doi. org/10.1111/j.1365-2265.2012.04468.x)

28 Fournier JP, Yin H, Yu OH \& Azoulay L. Metformin and low levels of thyroid-stimulating hormone in patients with type 2 diabetes mellitus. Canadian Medical Association Journal 2014186 1138-1145. (https://doi.org/10.1503/cmaj.140688)

29 Cappelli C, Rotondi M, Pirola I, Agosti B, Gandossi E, Valentini U, De Martino E, Cimino A, Chiovato L, Agabiti-Rosei E, et al. TSH-lowering effect of metformin in type 2 diabetic patients: differences between euthyroid, untreated hypothyroid, and euthyroid on L-T4 therapy patients. Diabetes Care 200932 1589-1590. (https://doi.org/10.2337/ dc09-0273)

30 Dos Santos PB, Gertrudes LN, Conceição FL, de Andrade BM, de Carvalho DP, Vaisman M \& Teixeira PFDS. Effects of metformin on TSH levels and benign nodular goiter volume in patients without insulin resistance or iodine insufficiency. Frontiers in Endocrinology 201910 465. (https://doi.org/10.3389/fendo.2019.00465)

31 Sui M, Yu Y, Zhang H, Di H, Liu C \& Fan Y. Efficacy of metformin for benign thyroid nodules in subjects with insulin resistance: a systematic review and meta-analysis. Frontiers in Endocrinology 20189 494. (https://doi.org/10.3389/fendo.2018.00494)

32 Dall'Asta C, Paganelli M, Morabito A, Vedani P, Barbieri M, Paolisso G, Folli F \& Pontiroli AE. Weight loss through gastric banding: effects on TSH and thyroid hormones in obese subjects with normal thyroid function. Obesity 201018 854-857. (https://doi.org/10.1038/ oby.2009.320)

33 Martinez-deMena R \& Obregón MJ. Insulin increases the adrenergic stimulation of $5^{\prime}$ deiodinase activity and mRNA expression in rat brown adipocytes; role of MAPK and PI3K. Journal of Molecular Endocrinology 200534 139-151. (https://doi.org/10.1677/ jme.1.01568)

34 Laclaustra M, Moreno-Franco B, Lou-Bonafonte JM, Mateo-Gallego R, Casasnovas JA, Guallar-Castillon P, Cenarro A \& Civeira F. Impaired sensitivity to thyroid hormones is associated with diabetes and metabolic syndrome. Diabetes Care 201942 303-310. (https://doi. org/10.2337/dc18-1410)

Received in final form 8 June 2021

Accepted 16 June 2021

Accepted Manuscript published online 17 June 2021 https://ec.bioscientifica.com https://doi.org/10.1530/EC-21-0218 (c) 2021 The authors Published by Bioscientifica Ltd

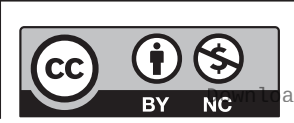

This work is licensed under a Creative Commons Attribution-NonCommercial 4.0 International License. ded from Bioscientifica,com at 04/26/2023 07:52:30AM 